\title{
Clinical utility of implantable neurostimulation devices in the treatment of chronic migraine
}

This article was published in the following Dove Press journal:

Medical Devices: Evidence and Research

19 November 2013

Number of times this article has been viewed

\author{
John A Freeman \\ Terrance L Trentman \\ Department of Anesthesiology, \\ Division of Pain Medicine, Mayo \\ Clinic Arizona, Phoenix, AZ, USA
}

Correspondence: John A Freeman Mayo Clinic Arizona, 5777 E Mayo Blvd, Phoenix, AZ 85054, USA

Email freeman.john@mayo.edu

\begin{abstract}
Chronic migraine is a disabling disorder that is costly to individuals and society. Occipital nerve stimulation has been used to treat refractory cases of primary headache disorders including drug-resistant chronic cluster headaches and chronic migraine. The Food and Drug Administration (FDA) off-labeled application of equipment used for peripheral nerve (occipital) stimulation is borrowed from FDA-labeled spinal cord stimulation. Manufacturer-sponsored randomized trials include a feasibility study (ONSTIM-Medtronic) and a safety and efficacy study (St Jude). A non-industry sponsored prospective, randomized crossover study by Serra and Marchiotretto suggests improved quality of life and a significant reduction in medication use. Though preliminary studies suggest occipital nerve stimulation is safe and efficacious in treating chronic migraine headache, complication rates, including lead migration, lead fracture, and surgical site infections remain high. Further studies are needed to demonstrate long-term outcomes, while improved surgical techniques and site-specific equipment are needed to minimize complications.
\end{abstract}

Keywords: headache, occipital nerve stimulation, peripheral nerve stimulation, neuromodulation, electrical stimulation therapy

\section{Introduction}

This review will discuss the anatomy, equipment, adverse events and outcome measures of occipital nerve stimulation (ONS) trials, with an emphasis on the clinical utility of implantable neurostimulation devices in the treatment of chronic migraine. Headache can be a chronic disabling disorder with profound personal and societal impact. Headache disorders are a worldwide problem, affecting people of all ages, ethnicities, socioeconomic classes, and geographical areas. ${ }^{1}$ Up to $4 \%$ of the world's adult population is affected by 15 or more headache days every month. ${ }^{2}$

Early civilizations must have recognized the impact of headache on their families and groups and sought relief through external intervention. Crude instrumentation and external manipulation is estimated to have occurred as early as 7,000 BC. Skull perforation through trepanation is evident not only in Neolithic skulls but continues to be practiced by some African tribes without anesthesia. ${ }^{3}$

In his $46 \mathrm{AD}$ text Compositiones Medicae, Scribonius Largus, a roman court physician to the emperor Claudius, described the use of torpedo fish (electric ray) to treat headache. ${ }^{4}$ This ancient account effectively demonstrates the earliest known use of primitive neuromodulation in headache.

In the late 20th century, progress was made by pioneers in neuromodulation. Picaza described his observational experience and patient outcomes who had undergone 
surgical procedures to expose and stimulate peripheral (sciatica, ulnar, and occipital) nerves. ${ }^{5}$ Based on this early work, a number of physicians have reported their experience with direct and indirect ONS. Subcutaneously implanted leads for occipital (peripheral) nerve stimulation have been used to treat headache disorders refractory to drug therapy. ${ }^{6-12}$ This includes chronic cluster headache, ${ }^{13-15}$ hemicrania continua, posttraumatic, occipital neuralgia, ${ }^{16,17} \mathrm{C} 2$-mediated headaches, ${ }^{18}$ and occipital region pain after surgery. ${ }^{9}$

The greater (GON) and lesser (LON) occipital nerves are the distal branches of C2-C3. ${ }^{19-23}$ These peripheral nerves ascend to the skull vertex by traversing an imaginary line between the mastoid processes. Cadaveric studies show the GON between 5 and $28 \mathrm{~mm}$ and the LON 32-90 $\mathrm{mm}$ from midline. Subcutaneous leads are placed along the intermastoid line at the occipital base ( $\mathrm{C} 1$ arch) and fixed subcutaneously to span this interval. Successful stimulation is achieved when the patient reports a "buzzing," "tingling," or pleasant vibratory sensation in the expected GON/LON dermatome. ${ }^{24}$ Painful paresthesias or shock can occur. ${ }^{13,15}$ Unilateral ONS in drug-resistant chronic cluster headache resulted in improvement; the attacks, however, shifted sides requiring bilateral stimulation. Unilateral ONS has also been linked with painless autonomic attacks and rapid recurrence with discontinuance of therapy. ${ }^{13}$ Literature review suggests that only bilateral ONS has been applied in CM.

\section{Methods}

The medical literature relevant to this review was identified by searching the Scopus, Embase (1988-2013 Week 12), and Ovid Medline reference databases for English-language articles published between 1996 and 2013 (last search Week 12). Search terms included "electrodes," "peripheral nerves," "electrical stimulation therapy" or "occipital nerve stimulation," "occipital stimulation," "electric stimulation therapy," "neuromodulation" and "headache," and "migraine disorders" or "neuralgia."

\section{Equipment}

The equipment used for ONS in the treatment of chronic migraine relies on the same technology as that used for spinal cord stimulation. The universal components include an implantable power source (ie, a battery) termed an internal pulse generator (IPG) or internal neurostimulator (INS), which is coupled with a programmable radiofrequency receiver. Rechargeable and non-rechargeable (ie, primary cell) batteries are available and are the approximate size and weight of cardiac implantable devices. Like the rechargeable batteries in many personal electronic devices, ONS rechargeable batteries will require more frequent recharging as they age. The IPG/INS for stimulation is implanted in a subcutaneous pocket in the chest, abdomen, or low back of the patient. ${ }^{25}$

The IPG is connected to insulated leads (ie, inert polyurethane-coated wires) that connect to an array of 4-16 metallic electrodes (ie, platinum iridium contacts) typically measuring between 3.0 and $6.0 \mathrm{~mm}$ in length, with interelectrode spacing (edge to edge) of 1-16 $\mathrm{mm}$. These electrodes are designed to function as non-charged (neutral) space, as anodes, or as cathodes. The configuration of arrays transmits an electrical current to the stimulation site. As previously noted, ONS is applied over the distal fibers of the C2-C3 dorsal rami GON and LON. Percutaneous leads with tubular contacts create a circumferential electrical field. They are inserted through a 14-gauge introducer needle. The leads may also be flat paddle leads, which are shorter and create a unilateral electrical field. Flat paddle leads require surgical dissection for placement and anchoring to the fascia. This may lead to additional bulk, wound complications, discomfort, or poor cosmetic outcome.

Migration of the leads (ie, bundled wires) can be prevented by suturing them to subcutaneous fascia with flexible anchors. In some cases, an extension cable (ie, a thin, coated wire) is required during implantation. This allows the surgeon to span an anatomical distance and/or provide coiled strainrelief loops during implantation of the leads connected to the distant IPG. Splitters can be used to divide electrical current to an additional anatomical site, such as right and left ONS or simultaneous occipital nerve and terminal trigeminal nerve stimulation. ${ }^{26,27}$

The IPG power source and programmable elements are activated by a handheld radiofrequency transmitter (ie, programmer). The programmer used by the clinician allows for the designation of cathodes and anodes as well as the programming of stimulation parameters and features including amplitude, pulse width, and frequency. A simplified programmer is used by the patient to turn the neurostimulator on or off, adjust power (amplitude), and select a preset program with set parameters in amplitude, pulse width, and frequency. Charging the IPG is completed via an external transmitter coil aligned over the device. Major manufacturers of the equipment in the United States include Boston Scientific Neuromodulation Corporation (Natick, MA, USA), Medtronic Inc. (Minneapolis, MN, USA), and St Jude Medical, Inc. (St Paul, MN, USA).

Some promising investigational ONS equipment that advanced to clinical trials has not been approved and is 
therefore not commercially available. For example, the Bion microstimulator (Boston Scientific Neuromodulation Corporation) was investigated for its use for chronic migraine. ${ }^{28,29}$ This "bionic neuron" contained a single anode/cathode configuration with a programmable microchip and a rechargeable lithium ion battery. The small size $(27.5 \mathrm{~mm} \times 3.2 \mathrm{~mm})$ of the self-contained microstimulator allowed it to be deployed adjacent to nerves via an introducer needle, and no additional internal hardware was required.

\section{Clinical indications}

The Food and Drug Administration (FDA) has approved neurostimulation technology for spinal cord stimulation in trunk and limb pain syndromes associated with failed back surgery syndrome and radiculopathy or limb pain associated with it. Additional approved indications include epidural fibrosis (ie, arachnoiditis) and complex regional pain syndromes (ie, reflex sympathetic dystrophy). The use of neurostimulator and microstimulator devices for ONS in the treatment of headache disorders such as chronic or transformed migraine is considered off-label use by the FDA. The ideal candidate for ONS is an adult with no contraindications who has well defined chronic migraine as defined by the International Headache Society's second edition International Classification of Headache Disorders. The patient would present with headache more than 15 days each month for longer than 3 months in the absence of medication overuse, would have pain involving the occipital or suboccipital region, and would be proven refractory to behavioral, preventive and abortive pharmacologic therapies. ${ }^{30}$ Diagnostic occipital nerve blocks have not been found to predict the efficacy of ONS. ${ }^{31}$

\section{Contraindications}

Contraindications to the use of ONS for chronic migraine include local or systemic infection, anticoagulant use, bleeding abnormalities, terminal illness, prior skull-based surgery, or anatomical abnormalities (eg, Chiari malformation). Patients with concurrent conditions requiring a demand cardiac pacemaker or automatic implantable cardioverterdefibrillator are precluded. Women who are pregnant, of childbearing age but not on contraception, or nursing are also not candidates for ONS. Additional ONS exclusion criteria include the probable future need for magnetic resonance imaging. ${ }^{30,32}$ The relationship between migraine and mood disorders is well researched. Many chronic migraineurs suffer from anxiety, depression, impulsive behaviors, and personality disorders. ${ }^{33}$ Specific pathologic psychiatric comorbidities that should be considered relative or absolute contraindications to ONS include personality disorders, suicidal tendencies, somatization or somatoform disorder, active substance abuse, or marked cognitive impairment; in these patients, psychological testing should be performed before initiating ONS. ${ }^{34}$

\section{Literature review}

In 2009, Boston Scientific presented preliminary results of the PRISM (Precision Implantable Stimulator for Migraine) study at societal meetings (Table 1). ${ }^{35}$ This multicenter, double-blind, randomized, sham-controlled study evaluated ONS for prevention of treatment-refractory migraine. Of 132 randomized subjects, 125 completed a 12-week period of either active or sham stimulation. However, active ONS did not prove to be superior to sham ONS. Pain relief during the pre-implantation 5- to 10-day trial was suggestive of benefit at the 12-week follow-up after permanent implantation. Adverse events included infection, sensory abnormalities, and pain.

In 2011, the findings from the ONSTIM (ONS for the treatment of intractable chronic migraine headache) trial were reported. ${ }^{30}$ This industry-sponsored, international, multicenter, randomized, blinded, controlled feasibility study was conducted to obtain preliminary safety and efficacy data on ONS in chronic migraine. Of 110 enrolled subjects, 75 were randomized to three treatment groups by a $2: 1: 1$ ratio: (1) adjustable stimulation (AS [n=33]), preset stimulation (PS [n = 17]), and medically managed (MM [n = 17]). A fourth, ancillary group ( $\mathrm{AG}[\mathrm{n}=8]$ ) met inclusion criteria but failed to respond to a diagnostic occipital nerve block. Three-month follow-up was available for all but two subjects (in the AG group). Stimulation parameters were variable in the ONSTIM feasibility study and were reported as pulse amplitude: $0.0-10.5 \mathrm{~V}$, pulse width $60-450 \mu \mathrm{s}$, and frequency 3-130 Hz.

Results for the 67 subjects who completed the 3-month blinded study showed ONS to be relatively safe with promising efficacy. The subsequent 36-month, open-label, long-term follow-up (with potential crossover) is yet to be completed and published as of this writing.

Safety objectives were measured by reporting adverse device-related events (ADEs) and non-ADEs. ADEs were collected on intraoperative testing and on scheduled and nonscheduled visits. Non-ADEs were collected at scheduled and nonscheduled visits. ADEs were subclassified into system components, surgical implant procedure, device programming, or device stimulation. Thirty-six of 51 (71\%) patients experienced a total of $56 \mathrm{ADE}$, the most frequent being lead migration $(n=12)$, infection of the lead or extension 
tract/site $(n=8)$, ineffective stimulation $(n=6)$, intraoperative incision site complication $(n=4)$, and INS pocket infection $(n=3)$.

Efficacy data (eg, headache days, headache-free days, and days with prolonged and severe headache) were collected by having each patient keep a daily diary. Additional observational data included headache pain intensity, headache duration, "responder rates" to ONS therapy, functional impairment (disability), Migraine Disability Assessment (MIDAS), SF-36, and subject satisfaction. Responder rates were defined as the percentage of subjects achieving a $50 \%$ or greater reduction in the number of headache days per month or a three-point or greater reduction in overall pain intensity compared with baseline. The responder rates were: AS 39\%, PS 6\%, MM 0\%, and AG 40\%. Exploratory analysis suggested mixed results for mood states, satisfaction, disability, and quality-of-life measurements. The AS group tended to have improved moods compared with their PS and MM counterparts. Most (60\%) AS subjects were satisfied, compared with only $25 \%$ of the MM subjects. Though the majority of the outcome measurements for disability and quality of life numerically favored the AS group, preliminary statistical analyses showed no clear advantage over the control groups.

Several randomized trials of ONS have been conducted recently. In 2011, Ellens and Levy described their experience with 2-year follow-up. ${ }^{36}$ Fifty prospective nonrandomized patients (45 of whom had chronic daily headache or chronic migraine) were implanted with ONS in an attempt to reduce pain and topographically map out which headache phenotype responded best to stimulation therapy. Most $(83 \%)$ reported "good to excellent" pain relief, and 9\% reported "satisfactory" pain relief. These patients reported they would be unwilling to have the device removed. A notable finding of this study was a lead migration or fracture rate of $66 \%$.

In 2012, Serra and Marchioretto ${ }^{32}$ published the results of their prospective crossover design randomized study of ONS for chronic migraine. Albeit a small, single-center study, patient outcomes at 1 year were encouraging, and the authors suggested that ONS was an immediately effective intervention for chronic migraine.

Patients enrolled in the study met diagnostic criteria for chronic migraine, and $85 \%$ underwent 2 months of drug detoxification for concomitant medication overuse headache. Of 34 enrolled patients, 30 proceeded to implantation if they experienced a successful trial with a quadripolar percutaneous lead, documented by their recording of a decrease of $50 \%$ or more in the number or severity of attacks.
Following permanent implantation of the INS (without lead revision), subjects were randomized 1:1 into "Arm A: INS ON" (active stimulation) or "Arm B: INS OFF" (inactive stimulation). The active stimulation parameters were frequency of $50 \mathrm{~Hz}$, pulse width $330-450 \mu$ s, and adjustable amplitude up to $10.5 \mathrm{~V}$. Crossover from "on" to "off" and vice versa occurred after 1 month. Patients in the "off" group were allowed to cross back to treatment ("on") at 2 months or sooner if they experienced a worsening of attacks of $30 \%$ or more on the Numeric Rating Scale (NRS-11). All patients ultimately finished in the "on" group.

Follow-up examinations were scheduled at months 1, 3, 6, and 12. Measures of improvement included the MIDAS, the SF-36 (quality of life), the (NRS-11), and a headache diary. Of the 29 subjects who completed the 1-year study, all had improvement on all measures, including drug intake documented in the diary. MIDAS scores improved from 79 at baseline to 10. The greatest improvements in the Short Form36 domains were in the areas of Role Physical, Bodily Pain, Social Functioning, Role Emotional, and Mental Health. The median monthly dose of triptans per month decreased from 20 at baseline to 3 . The doses per month of nonsteroidal anti-inflammatory drugs decreased from 25.5 at baseline to 2.0. Adverse events were minimal, with only five recorded: two severe implantation site infections (ie, presumed INS pocket), and 3 of 30 (10\%) lead dislocations (ie, migration) that required repositioning without apparent long-term complications or nerve injury.

A second 2012 report with positive support for ONS as a headache treatment was Silberstein et al's ${ }^{37}$ summary of their findings from a prospective, controlled study of PNS for migraine. Of 268 subjects enrolled over a 5-year period, 157 were permanently implanted with a percutaneous (cylindrical) lead after a successful temporary trial. These patients then underwent block randomization 2:1 into an active group $(n=105)$ and a control group $(n=52)$. The primary outcome measure at 12 weeks in both groups was the visual analog scale (VAS). "Responders" were those subjects who experienced $50 \%$ or greater improvement in VAS without an increase in headache duration. Secondary outcome measures were the reduction in the number of headache days, MIDAS questionnaire; patient-reported headache pain relief, and adverse events. No patients were lost to follow up; four, however, discontinued the study due to adverse events, including lead migration $(20 / 157 ; 18.7 \%)$ and persistent pain or numbness at the IPG/lead site $(23 / 157 ; 21.5 \%)$.

Silberstein et al reported no statistical difference for the primary endpoint. There were 18 responders $(17.1 \%)$ to PNS/ 
Table I Summary of prospective controlled trials of occipital nerve stimulation for migraine

\begin{tabular}{|c|c|c|c|c|c|}
\hline Author, (study) & Study design & $\begin{array}{l}\text { Number of enrolled/ } \\
\text { randomized patients }\end{array}$ & $\begin{array}{l}\text { Primary outcome } \\
\text { measure }\end{array}$ & Secondary measures & Results \\
\hline $\begin{array}{l}\text { Saper et al } \\
(\text { ONSTIM) })^{30}\end{array}$ & $\begin{array}{l}\text { Multicenter, } \\
\text { randomized, } \\
\text { blinded, controlled } \\
\text { feasibility study }\end{array}$ & $\begin{array}{l}\text { II0/75 } \\
\text { Randomized/implanted/ } \\
\text { 3-month follow up } \\
\text { Active stim 33/29/29 } \\
\text { Preset stim 17/16/16 } \\
\text { Medical I7/0/17 } \\
\text { Ancillary 8/6/5 }\end{array}$ & $\begin{array}{l}\text { Observational data } \\
\text { collection via diary: } \\
\text { number of headache } \\
\text { attacks; number of days } \\
\text { per week with headache; } \\
\text { and headache severity } \\
\text { and duration }\end{array}$ & $\begin{array}{l}\text { Observational data } \\
\text { collections via diary: } \\
\text { responder rates, POMS, } \\
\text { MIDAS, SF-36, functional } \\
\text { MIDAS, quality of life, } \\
\text { functional impairment, } \\
\text { disability and subject } \\
\text { satisfaction scores }\end{array}$ & $\begin{array}{l}68 \text { patients implantec } \\
67 \text { analyzed at } \\
3 \text { months. ONS for } \\
\text { chronic migraine } \\
\text { warrants further } \\
\text { investigation }\end{array}$ \\
\hline $\begin{array}{l}\text { Silberstein et al } \\
\text { (safety and efficacy } \\
\text { of peripheral nerve } \\
\text { stimulation of the } \\
\text { occipital nerves for } \\
\text { the management of } \\
\text { chronic migraine) }\end{array}$ & $\begin{array}{l}\text { Randomized, multi- } \\
\text { center, double- } \\
\text { blind, placebo- } \\
\text { controlled }\end{array}$ & $\begin{array}{l}\text { 268/I57 } \\
\text { Two active/one sham }\end{array}$ & $\begin{array}{l}\geq 50 \% \text { decrease in VAS } \\
\text { at } 12 \text { weeks }\end{array}$ & $\begin{array}{l}\text { Number of headache } \\
\text { days, MIDAS, headache } \\
\text { pain relief, and AEs }\end{array}$ & $\begin{array}{l}\text { I } 53 \text { completed the } \\
\text { study, I57 analyzed } \\
\text { at I } 2 \text { weeks. Study } \\
\text { failed to meet } \\
\text { primary endpoint }\end{array}$ \\
\hline $\begin{array}{l}\text { Serra and } \\
\text { Marchioretto } \\
\text { (Occipital nerve } \\
\text { stimulation for } \\
\text { chronic migraine: } \\
\text { a randomized trial) } \text { ) }^{32}\end{array}$ & $\begin{array}{l}\text { Prospective, } \\
\text { randomized } \\
\text { crossover design }\end{array}$ & $34 / 30$ & $\begin{array}{l}\text { Data collection via } \\
\text { diary: number of headache } \\
\text { attacks; number of days/ } \\
\text { week with headache; } \\
\text { headache severity }\end{array}$ & $\begin{array}{l}\text { MIDAS, SF-36, } \\
\text { medication intake, and } \\
\text { AEs }\end{array}$ & $\begin{array}{l}\text { 29; I-year endpoint } \\
\text { ONS appears safe } \\
\text { and effective for } \\
\text { chronic migraine }\end{array}$ \\
\hline
\end{tabular}

Abbreviations: AE, adverse event; MIDAS, Migraine Disability Assessment; ONS, occipital nerve stimulation; POMS, Profile of Mood States; SF-36, Short Form-36; VAS, visual analog scale.

ONS in the active group compared with seven (13.5\%) in the control group. The authors argued, however, that a clinically significant difference was seen between the groups at the $30 \%$ reduction in VAS level, which the International Headache Society has established as clinically meaningful. Secondary outcome measures favored the active group because more of those subjects rated their headache pain relief as "good" or "excellent."35

\section{Clinical implications and future directions}

Chronic migraine is a complex phenomenon with both peripheral and central manifestations. The pathophysiology of chronic migraine is not well defined, and the mechanism by which patients with chronic migraine respond to ONS is unknown. Extrapolation of Melzack and Wall's ${ }^{38} 1965$ Gate Theory of Pain would suggest that wide-dynamic range neurons from the $\mathrm{C} 2$-innervated somatic structures affect trigeminal afferent nerves, hence modulating dura-vascular nociception..$^{30,39,40}$ ONS is of great interest to the pain management and neurology headache communities because of its potential benefit to otherwise-refractory headache patients. Patients considered for ONS therapy have failed psychological, medical, and other interventional approaches to pain relief. Significant obstacles remain before ONS can be considered a routine option in patients affected with this difficult problem. Large controlled studies showing durable benefit over placebo are needed. The response to placebo is likely high in any intervention, especially ONS, as the patient may or may not perceive stimulation after implantation. ${ }^{41}$ Future studies and technical reviews should demonstrate surgical techniques to reduce the incidence of lead migration. Medical device manufacturers should develop equipment (leads, anchors, extensions, and pulse generators) specific to the application, which may minimize complications such as lead migration, fracture, infection, and poor cosmetic outcome.

This clinical review suggests that ONS has a viable place in the management of chronic migraine. Currently, expense for this non-FDA-approved indication is a significant barrier. The relatively fixed surgical and device cost of ONS must be measured against the financial expense of chronic pharmacologic therapy and the societal cost in lost work, impaired quality of life and disability. Future application of ONS may also include concomitant stimulation of the trigeminal nerve distal division including the supraorbital, the supratrochlear, and the temporal auricular nerves associated with refractory, severe headache disorders. ${ }^{40,42,43}$ Specialists from multiple disciplines should participate and contribute to this growing fund of knowledge.

\section{Disclosure}

The authors report no conflicts of interest in this work. 


\section{References}

1. Lipton RB, Stewart WF, Diamond S, Diamond ML, Reed M. Prevalence and burden of migraine in the United States: data from the American Migraine Study II. Headache. 2001;41(7):646-657.

2. Organization WH. Global Burden of Disease Study. Available from: http://www.who.int/mediacentre/factsheets/fs277/en. Accessed April 22, 2013.

3. Silberstein SD, Lipton RB, Goadsby PJ. Headache in Clinical Practice. 2nd ed. UK: Martin Dunitz Ltd; 2002.

4. Bullock TH, Hopkins CD, Popper AN, Fay RR, editors. Electroreception. 2005 ed: Springer; 2005.

5. Picaza JA, Hunter SE, Cannon BW. Pain suppression by peripheral nerve stimulation. Chronic effects of implanted devices. Appl Neurophysiol. 1977;40(2-4):223-234.

6. Young WB, Silberstein SD. Occipital nerve stimulation for primary headaches. J Neurosurg Sci. 2012;56(4):307-312.

7. Son BC, Yang SH, Hong JT, Lee SW. Occipital nerve stimulation for medically refractory hypnic headache. Neuromodulation. 2012;15(4): 381-386.

8. Vadivelu S, Bolognese P, Milhorat TH, Mogilner AY. Occipital nerve stimulation for refractory headache in the Chiari malformation population. Neurosurgery. 2012;70(6):1430-1436; discussion 1436-1437.

9. Hammer M, Doleys DM. Perineuromal stimulation in the treatment of occipital neuralgia: a case study. Neuromodulation. 2001;4(2):47-51.

10. Oh MY, Ortega J, Bellotte JB, Whiting DM, Alo K. Peripheral nerve stimulation for the treatment of occipital neuralgia and transformed migraine using a c1-2-3 subcutaneous paddle style electrode: a technical report. Neuromodulation. 2004;7(2):103-112.

11. Popeney CA, Alo KM. Peripheral neurostimulation for the treatment of chronic, disabling transformed migraine. Headache. 2003;43(4): 369-375.

12. Rodrigo-Royo MD, Azcona JM, Quero J, Lorente MC, Acin P, Azcona J. Peripheral neurostimulation in the management of cervicogenic headache: four case reports. Neuromodulation. 2005;8(4):241-248.

13. Magis D, Gerardy PY, Remacle JM, Schoenen J. Sustained effectiveness of occipital nerve stimulation in drug-resistant chronic cluster headache. Headache. 2011;51(8):1191-1201.

14. Magis D, Allena M, Bolla M, De Pasqua V, Remacle JM, Schoenen J. Occipital nerve stimulation for drug-resistant chronic cluster headache: a prospective pilot study. Lancet Neurol. 2007;6(4):314-321.

15. Burns B, Watkins L, Goadsby PJ. Treatment of medically intractable cluster headache by occipital nerve stimulation: long-term follow-up of eight patients. Lancet. 2007;369(9567):1099-1106.

16. Waisbrod H, Panhans C, Hansen D, Gerbershagen HU. Direct nerve stimulation for painful peripheral neuropathies. J Bone Joint Surg Br. 1985;67(3):470-472.

17. Weiner RL, Reed KL. Peripheral neurostimulation for control of intractable occipital neuralgia. Neuromodulation. 1999;2(3):217-221.

18. Melvin EA Jr, Jordan FR, Weiner RL, Primm D. Using peripheral stimulation to reduce the pain of C2-mediated occipital headaches: a preliminary report. Pain Physician. 2007;10(3):453-460.

19. Johnstone CS, Sundaraj R. Occipital nerve stimulation for the treatment of occipital neuralgia-eight case studies. Neuromodulation. 2006;9(1):41-47.

20. Becser N, Bovim G, Sjaastad O. Extracranial nerves in the posterior part of the head. Anatomic variations and their possible clinical significance. Spine (Phila Pa 1976). 1998;23(13):1435-1441.

21. Bogduk N. The clinical anatomy of the cervical dorsal rami. Spine (Phila Pa 1976). 1982;7(4):319-330.

22. Bogduk N. The anatomy of occipital neuralgia. Clin Exp Neurol. 1981;17:167-184.
23. Natsis K, Baraliakos X, Appell HJ, Tsikaras P, Gigis I, Koebke J. The course of the greater occipital nerve in the suboccipital region: a proposal for setting landmarks for local anesthesia in patients with occipital neuralgia. Clin Anat. 2006;19(4):332-336.

24. Trentman TL, Zimmerman RS. Occipital nerve stimulation: technical and surgical aspects of implantation. Headache. 2008;48(2):319-327.

25. Trentman TL, Zimmerman RS, Dodick DW. Occipital nerve stimulation: technical and surgical aspects of implantation. Prog Neurol Surg. 2011;24:96-108.

26. Piovesan EJ, Kowacs PA, Tatsui CE, Lange MC, Ribas LC, Werneck LC. Referred pain after painful stimulation of the greater occipital nerve in humans: evidence of convergence of cervical afferences on trigeminal nuclei. Cephalalgia. 2001;21(2):107-109.

27. Deshpande KK, Wininger KL. Feasibility of combined epicranial temporal and occipital neurostimulation: treatment of a challenging case of headache. Pain Physician. 2011;14(1):37-44.

28. Trentman TL, Rosenfeld DM, Vargas BB, Schwedt TJ, Zimmerman RS, Dodick DW. Greater occipital nerve stimulation via the Bion microstimulator: implantation technique and stimulation parameters. Clinical trial: NCT00205894. Pain Physician. 2009;12(3):621-628.

29. Strand NH, Trentman TL, Vargas BB, Dodick DW. Occipital nerve stimulation with the Bion(R) microstimulator for the treatment of medically refractory chronic cluster headache. Pain Physician. 2011;14(5): 435-440.

30. Saper JR, Dodick DW, Silberstein SD, McCarville S, Sun M, Goadsby PJ. Occipital nerve stimulation for the treatment of intractable chronic migraine headache: ONSTIM feasibility study. Cephalalgia. 2011;31(3):271-285.

31. Schwedt TJ, Dodick DW, Trentman TL, Zimmerman RS. Response to occipital nerve block is not useful in predicting efficacy of occipital nerve stimulation. Cephalalgia. 2007;27(3):271-274.

32. Serra G, Marchioretto F. Occipital nerve stimulation for chronic migraine: a randomized trial. Pain Physician. 2012;15(3):245-253.

33. Olesen J, Goadsby PJ, Ramadan NM, Tfelt-Hansen P, Welch KM, editors. The Headaches. 3rd ed. Philadelphia: Lippincott Williams \& Wilkins; 2006.

34. Kreis P, Fishman S. Spinal Cord Stimulation Percutaneous Implantation Techniques. Oxford: Oxford University Press; 2009.

35. Schwedt TJ, Silberstein SD. 14th International Headache Congress: clinical highlights. Headache. 2010;50(3):509-519.

36. Ellens DJ, Levy RM. Peripheral neuromodulation for migraine headache. Prog Neurol Surg. 2011;24:109-117.

37. Silberstein SD, Dodick DW, Saper J, et al. Safety and efficacy of peripheral nerve stimulation of the occipital nerves for the management of chronic migraine: results from a randomized, multicenter, doubleblinded, controlled study. Cephalalgia. 2012;32(16):1165-1179.

38. Melzack R, Wall PD. Pain mechanisms: a new theory. Science. 1965;150(3699):971-979.

39. Bartsch T, Goadsby PJ. Central mechanisms of peripheral nerve stimulation in headache disorders. Prog Neurol Surg. 2011;24:16-26.

40. Jenkins B, Tepper SJ. Neurostimulation for primary headache disorders, part 1: pathophysiology and anatomy, history of neuromodulation in headache treatment, and review of peripheral neuromodulation in primary headaches. Headache. 2011;51(8):1254-1266.

41. Schwedt TJ. Occipital nerve stimulation for chronic migraine-interpreting the ONSTIM feasibility trial. Cephalalgia. 2011;31(3):262-263.

42. Magis D, Jensen R, Schoenen J. Neurostimulation therapies for primary headache disorders: present and future. Curr Opin Neurol. 2012;25(3): 269-276.

43. Simopoulos T, Bajwa Z, Lantz G, Lee S, Burstein R. Implanted auriculotemporal nerve stimulator for the treatment of refractory chronic migraine. Headache. 2010;50(6):1064-1069. 
Medical Devices: Evidence and Research

Dovepress

\section{Publish your work in this journal}

Medical Devices: Evidence and Research is an international, peerreviewed, open access journal that focuses on the evidence, technology, research, and expert opinion supporting the use and application of medical devices in the diagnosis, treatment and management of clinical conditions and physiological processes. The identification of novel devices and optimal use of existing devices which will lead to improved clinical outcomes and more effective patient management and safety is a key feature. The manuscript management system is completely online and includes a quick and fair peer-review system. Visit http://www. dovepress.com/testimonials.php to read real quotes from authors.

Submit your manuscript here: http://www.dovepress.com/medical-devices-evidence-and-research-journal 